\title{
IONOSPHERIC EFFECT OF NON-STORM HILDCAA (HIGH INTENSITY LONG DURATION CONTINUOUS AURORAL ACTIVITY)
}

\section{Binod Adhikari, Roshan Kumar Mishra, Drabindra Pandit, Binod Bhattarai, and Narayan Prasad Chapagain}

Journal of Institute of Science and Technology

Volume 22, Issue 1, July 2017

ISSN: $2469-9062$ (print), 2467-9240 (e)

Editors:

Prof. Dr. Kumar Sapkota

Prof. Dr. Armila Rajbhandari

Assoc. Prof. Dr. Gopi Chandra Kaphle

JIST, 22 (1): 34-40 (2017)

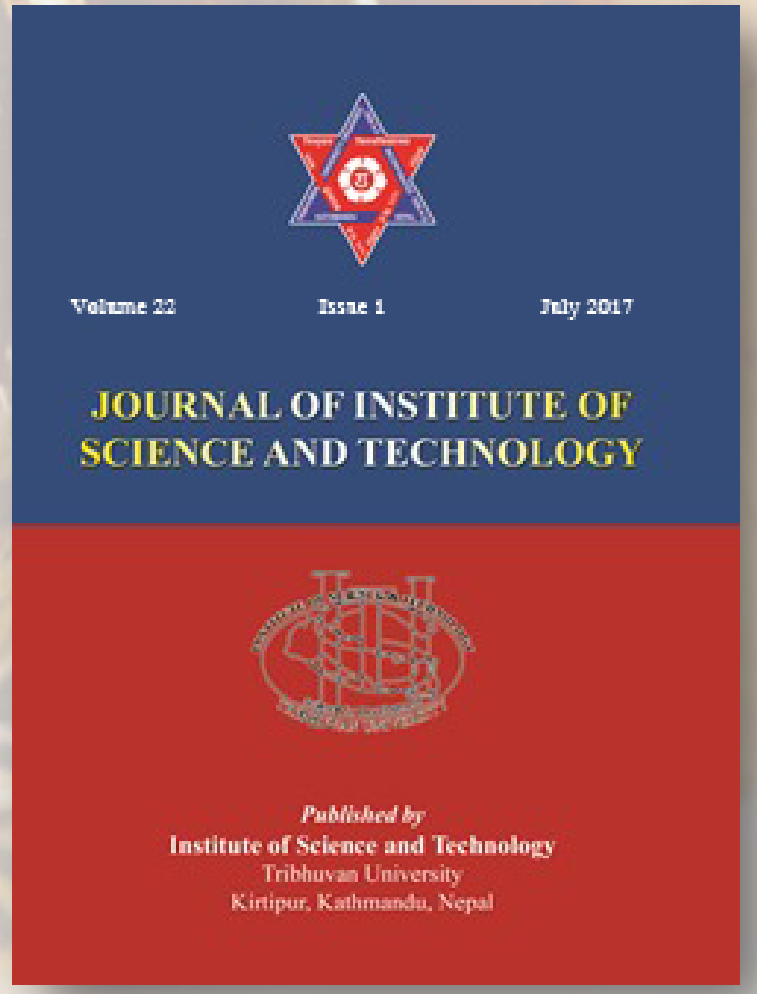

Published by:

Institute of Science and Technology

Tribhuvan University

Kirtipur, Kathmandu, Nepal 


\title{
IONOSPHERIC EFFECT OF NON-STORM HILDCAA (HIGH INTENSITY LONG DURATION CONTINUOUS AURORAL ACTIVITY)
}

\author{
Binod Adhikari ${ }^{1,2,}$, Roshan Kumar Mishra ${ }^{2}$, Drabindra Pandit ${ }^{2}$, Binod Bhattarai ${ }^{2}$, \\ and Narayan Prasad Chapagain ${ }^{1}$ \\ ${ }^{1}$ Patan Multiple Campus, Patandhoka, Lalitpur, Nepal \\ ${ }^{2}$ St. Xavier's College, Maitighar, Kathmandu, Nepal \\ "Corresponding E-mail: binod.adhi@gmail.com
}

\begin{abstract}
The magnetosphere of the Earth is temporarily changed by geomagnetic disturbances. Geomagnetic disturbances are caused by solar wind, shock wave or clouds of solar magnetic field. During their interactions energy is transferred into the magnetosphere. Apart from this, solar wind pressure also compresses the magnetosphere. Both kinds of interactions cause an increase in plasma movement through the magnetosphere and ionosphere. The geomagnetic disturbances may sustain for a few minutes to many hours depending upon the intensity of energy and particles released from the Sun. The geomagnetic disturbances are measured by geomagnetic indices for short periods of time. In this work, we discuss the impact of peculiar type of geomagnetic disturbances known as high intensity long duration continuous auroral activity on the Earth's ionosphere. This analysis leads to understand the impact on communication system due to coupling between solar terrestrial environments. It will also broaden the various aspects on how ionospheric critical frequency (foF2), F2 layer peak density height (hmF2), high frequency (hF) and horizontal component of earth magnetic field can be lifted from lower to higher altitudes.
\end{abstract}

Keywords: Geomagnetic disturbances, HILDCAA, Coupling, Ionospheric parameters, Wavelet transform.

\section{INTRODUCTION}

Electric current in ionosphere and magnetosphere plays a significant role in the magnetic field of the Earth (Chapman \& Bartels, 1962). Different solar activities change the current system in entire magnetosphere and ionosphere which causes variation in the Earth's magnetic field called geomagnetic disturbance (Guarnieri et al., 2006). The magnetic reconnection between southward interplanetary magnetic field (IMF) and Earth's dayside magnetic field is the key reason for geomagnetic disturbances, which give rise to an electrodynamics coupling between the solar plasma and the magnetosphere (Dungey, 1961; Gonzalez et al., 1994; Adhikari \& Chapagain, 2016; Adhikari et al., 2017). The solar sources of the geomagnetic disturbances are known to have various interplanetary manifestations like coronal mass ejection (ICMEs), magnetic clouds, co-rotating interaction region (CIR) and other interplanetary structures like interplanetary shocks (IPS), heliospheric current sheet (HCS) and sector boundary (SB) (Wei et al., 1994; Gonzalez et al., 1999; Klein \& Burlaga, 1982).

The energy released in the atmosphere in course of the violent magnetic storms may lead to reduction of lifetime of low Earth orbiting satellite, satellite communication failure, data loss and navigation errors. GPS measurement and geophysical surveys may give errors. Due to high radiation and lack of contact with the ground station the space travelers have maximum chance of radiation exposure. The intense magnetic storm may damage power transmission lines and erode the pipelines and cables. Space crafts may not respond to their respective stations. Such violent magnetic storms may have devastating effects on human life and technological system (Lakhina et al., 2005). Coronal holes occur frequently during descending and minimum phases of solar cycle, radiating high speed streams constituting of highly fluctuating Alfen waves, of velocities greater than typical solar wind. Their difference gives rise to interface region, Corotating Interaction Region (CIRs), in the interplanetary medium. These high speed 
streams initiate moderate geomagnetic storm as a result of high fluctuations in the southward oriented $\mathrm{B}_{\mathrm{z}}$-component of the Interplanetary Magnetic Field (IMF). With decrease in the fluctuation in $\operatorname{IMF}\left(\mathrm{B}_{\mathrm{z}}\right)$, the storm results in prolonged recovery phase. HILDCAA (High Intensity Long Duraion Continuous AE activity) is defined as prolongation in duration of high intensity and continuous auroral activities. (Tsurutani \& Gonzalez, 1987; Tsurutani et al., 2004; Guarnieri et al., 2006; Hajra et al., 2013; Hajra et al., 2014a; Hajra et al., 2014b; Adhikari \& Chapagain, 2016). The auroral activity can be measured by the AE (auroral electrojet) index, which monitors the horizontal component of disturbed magnetic field in the auroral zone (Rostoker, 1972). Tsurutani and Gonzalez (1987) defined HILDCAA events as intervals where: (1) AE peak values exceed $1000 \mathrm{nT}$, (2) the durations were greater than 2 days, (3) the $\mathrm{AE}$ values never dropped below $200 \mathrm{nT}$ for more than $2 \mathrm{~h}$ at a time, (4) HILDCAAs must occur outside of the main phases of magnetic storms. Our knowledge regarding the effects of HILDCAA on the ionosphere is inadequate. The daily and seasonal variation in geomagnetic parameters is also produced by fluctuation of current in ionosphere (Adhikari et al., 2017). In this paper we analyzed the effect of HILDCAA. The dataset were taken from Tacuamionospheric station in Argentina and magnetometer data form Vassouras station in Brazil. The present study is also an effort to extrapolate the effects of HILDCAA events on electric fields and thermospheric winds.

\section{DATASET AND METHODOLOGY}

In this paper, we have analyzed the impacts of HILDCAA on ionospheric $F_{2}$ layer and ground magnetometer during 20-23 April 2003. For this work, the solar wind, ionospheric (for Tucuam stations) and magnetometer (for Vassouras stations) datasets were downloaded from the web pages: www.omni.nasa.org, www.cdaweb.gsfc.nasa.gov and www.intermagnet.org respectively.

\section{Discrete Wavelet Transform (DWT):}

For proper interpretation, discrete and continuous wavelet analysis have used. DWT techniques like Harr wavelet reflect the drastic fluctuation in the geomagnetic field (Daubechies, 1992; Chui 1992). In order to analyze the local disturbances in the signal, we took Daubechies wavelet coefficients
(Gonzalez et al., 1994, Kalausner et al., 2014). The advantage of this method is it can detect the first order disturbances along with its derivatives (Adhikari \& Chapagain, 2016). DWT is not only used to find the change in signal but also to detectthe singularities present in signals. Besides this, it also detects the singularities presence in the signals (Domingues et al., 2005; Mendes et al., 2005). The larger and smaller values of amplitude of wavelet coefficients direct the energy deposited in the ring current and also show their localized positions (Klausner et al., 2014). The highest and lowest values of square wavelet coefficient during acute active stage and quiet condition are their indicators.

\section{Continuous Wavelet Transform (CWT)}

CWT is used to provide the reliable description of the signal in term of time and frequency domain. In this transformation a continuous signal is expressed into wavelets (Grassmann \& Morlet, 1983; Adhikari \& Chapagain, 2016). The CWT coefficientisis defined as

$$
\mathrm{W}(\mathrm{a}, \mathrm{b})=\int \mathrm{f}(\mathrm{t}) \varphi^{*}((\mathrm{t}-\mathrm{b}) / \mathrm{a}) \mathrm{dt} ;
$$

Where $\varphi^{*}$ represents the complex conjugate of $\varphi$ and the parameters $a$ and $b$ are scaling and shifting factors respectively and $\mathrm{W}(\mathrm{a}, \mathrm{b})$ gives the values of the coefficients. The duration of the high and low frequency is identified by this technique.

\section{RESULTS AND DISCUSSION}

In figure 1, from top to bottom the panels represent the variation of ionospheric parameters foF2, hF, hmF2 and $\Delta \mathrm{H}$-component along with the geomagnetic indices SYM-H (nT), ASY-H (nT) and AE (nT) respectively for 109-115 days of the year 2003. The figure indicates that the HILDCAA event starts at the mid-day of $110^{\text {th }}$ $\left(20^{\text {th }}\right.$ April, 2003) day to the beginning of $113^{\text {th }}$ day $\left(23^{\text {th }}\right.$ April, 2003). The figure also shows that there is a great fluctuation in the values of ionospheric parameters. Variation on foF2 seems to follow a regular pattern whereas the value of $\mathrm{hF}$ and $\mathrm{hmF} 2$ is maximum on the mid-day of $111^{\text {th }}$ day. The horizontal component of Earth magnetic field also shows fluctuation during this event. The SYM-H index shows depression in its values below the reference level whereas ASY-H has positive values with a maximum of about 85 $\mathrm{nT}$. The AE index shows intense activity from mid-day of $110^{\text {th }}$ day to the beginning of $113^{\text {th }}$ day. 

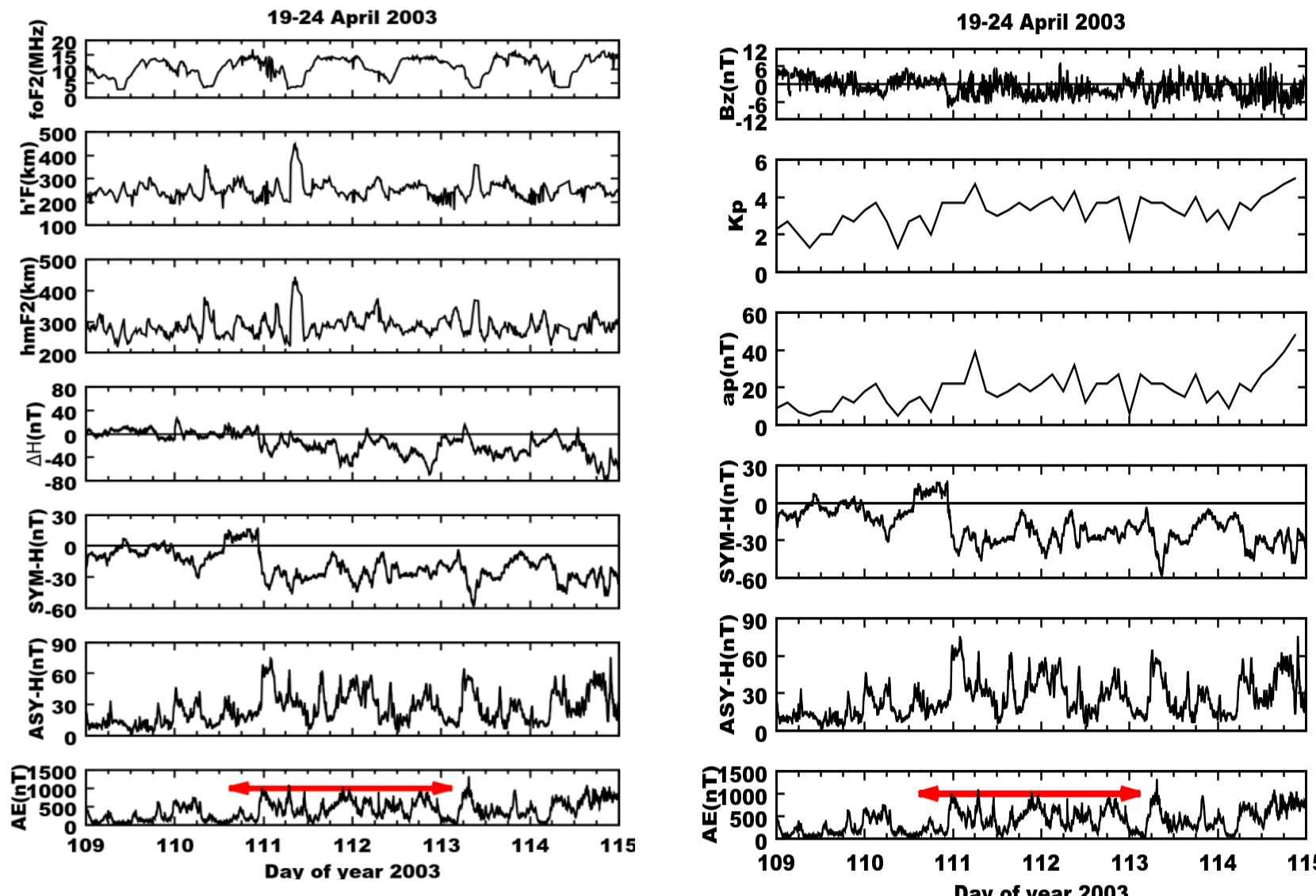

Fig. 1. The variation of ionospheric parameters foF $2, h F, h m F 2$ and $\triangle H(n T)$ component along with the geomagnetic indices SYM-H (nT), ASY-H

(nT) and $A E(n T)$ respectively during HILCAA event on 20-23 April, 2003. The red horizontal arrow in $A E$ panel indicates the HILDCAA interval.
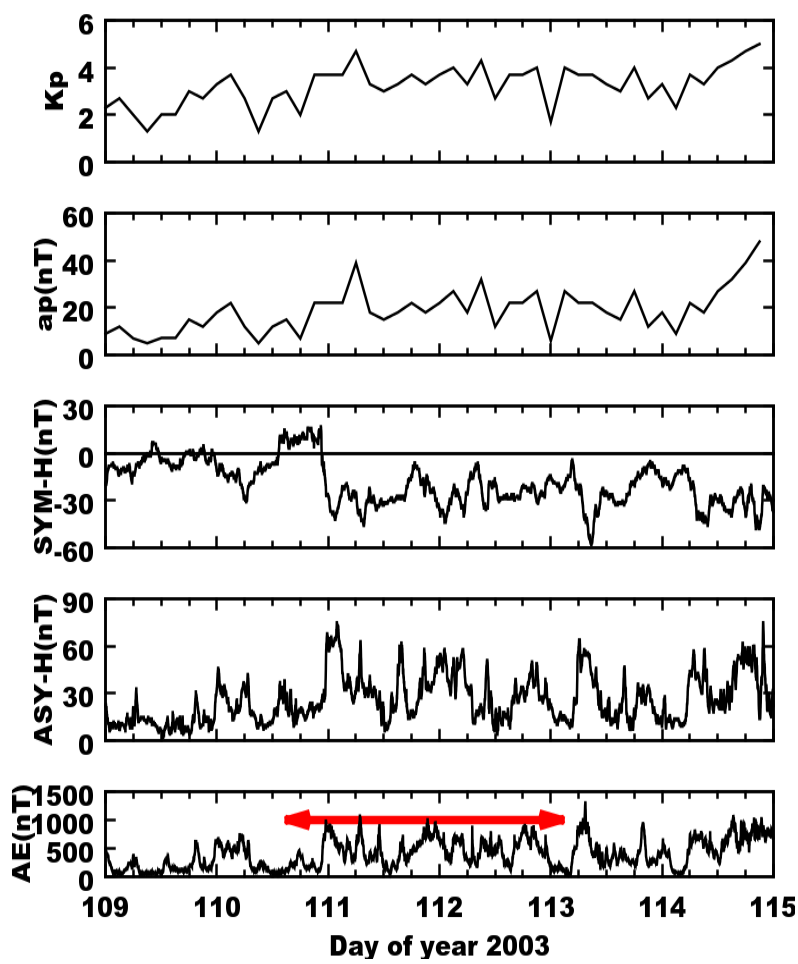

Fig. 2. The variation of IMF-Bz (nT) and geomagnetic indices Kp, ap (nT), SYM-H (nT), $A S Y-H(n T)$ and $A E(n T)$ respectively during HILCAA event on 20-23 April, 2003 and the red horizontal arrow in $A E$ panel indicates the HILDCAA interval.

CWT Analysis

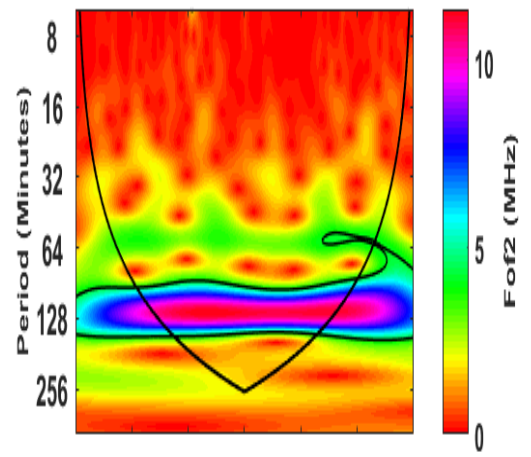

$\begin{array}{llllll}110 & 111 & 112 & 113 & 114 & 115\end{array}$ Time(Day of the yearl)

(a)

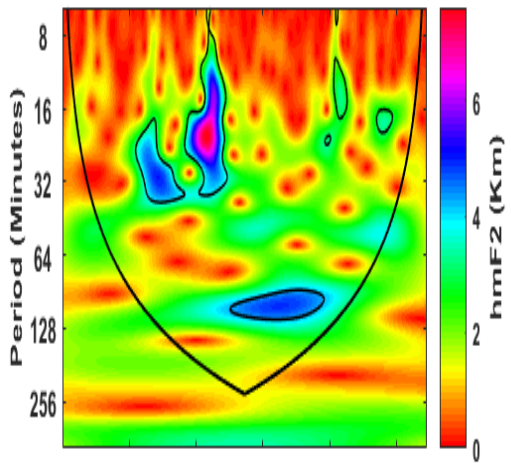

$\begin{array}{lllll}110 & 111 & 112 & 113 & 114\end{array}$ Time (Day of the yearl)

(b)

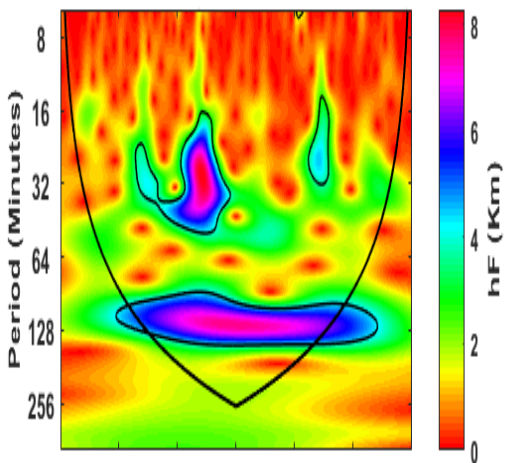

$110 \quad 111 \quad 112 \quad 113 \quad 114 \quad 115$ Time (Day of the year)

(c)

Fig. 3. Scalograms for ionospheric critical frequency (foF2), F2 layer peak density height (hmF2) and high frequency $(\mathrm{hF})$ during the 109-115 days of the year 2003. 
Figure 3(a), (b) and (c) represent the Scalograms for ionospheric critical frequency (foF2), F2 layer peak density height $(\mathrm{hmF} 2)$ and high frequency $(\mathrm{hF})$ during the 109-115 days of the year 2003. The same data sets that we presented above are used. The signal energy in wavelet space represented in the scalograms is imagined using a $\log 2$ function that highlights likewise little irritations. In the figures, the horizontal axis represents the time in days and the vertical axis represents the periodicity in minutes. The amplitude represented in the plot whose color are demonstrated on the right side for F2 layer peak density height (hmF2), high frequency $(\mathrm{hF})$ and ionospheric critical frequency (foF2). Breaking down the scalograms, the characteristic of ionospheric critical frequency (foF2) demonstrates continuous periodicities throughout our significance zone. F2 layer peak density height $(\mathrm{hmF} 2)$ demonstrates a high variability in periodicities and high frequency $(\mathrm{hF})$ demonstrates moderate variability with time without presence of continuous periodicities. The power ranges of higher intensity were seen continuously for more than a day for the ionospheric critical frequency (fOF2) and high frequency $(\mathrm{hF})$. For instance, the power zones of the highest intensity for the F2 layer peak density height $(\mathrm{hmF} 2)$ has been observed at time period between 16 to 26 minutes with peak intensity of 7 to $8 \mathrm{Km}$ during the starting of the day 111 which is completely inside our significance zone.

Similarly, the power areas for the high frequency $(\mathrm{hF})$ are between periods of 110 to 128 minutes with peak intensity reaching up to 7 to $8 \mathrm{Km}$ starting early from $111^{\text {th }}$ day to afternoon of $113^{\text {th }}$ day. Another power area has also been observed with a period of 20 to 40 minutes with peak intensity reaching up to 7 to $8 \mathrm{Km}$ as above starting from morning of day 111 and ending later at night of the same day. The observation of two different power areas with same peak intensity but with different periodicities at the same time suggests that two activities of significant effect have occurred during that time of the day.

The ionospheric critical frequency (foF2) seems to follow a regular periodicity of 110 to 128 minutes with the peak intensity reaching up to $10 \mathrm{MHz}$ throughout the days of 111, 112 and 113.

The event follows the regular pattern on the starting of day 111 to the end of the day 113 which however lies outside our significance zone. It is notable that for all the parameters, the variation on foF2 seems to follow a regular pattern whereas the values of $\mathrm{hF}$ and $\mathrm{hmF} 2$ are maximum on the mid-day of 111th day. These results show that periodicity is expressing almost continuously throughout 110 to 128 minute scale of periodicity for ionospheric critical frequency (foF2) and high frequency (hF). However, at the period scales above 16, we can see periodicity is expressing highly discontinuously throughout the days. Considering the relation of periodicity and frequency, the zones where periodicity was found to be less are more frequent. Finding a zone with less periodicity and high peak intensity could be of our interest which is significant for $\mathrm{F} 2$ layer peak density height $(\mathrm{hmF} 2)$ and high frequency $(\mathrm{hF})$ where periods of 16 to 26 minutes and 20 to 40 minutes was found respectively with a peak intensity of 7 to $8 \mathrm{Km}$. Finding a peak intensity of such a high value at low periodicity strongly suggests F2 layer peak density height $(\mathrm{hmF} 2)$ and high frequency $(\mathrm{hF})$ are significantly demonstrating an intense activity. Figure 2 is similar to figure 1 with respect to its variation on geomagnetic indices. Moreover, it shows that during HILDCAA events, the component of magnetic field shows high level of fluctuations due to the presence of Alfven waves (Guarnieri et al., 2006). This fact can also be corroborated by fluctuations in density and speed of the solar wind plasma.
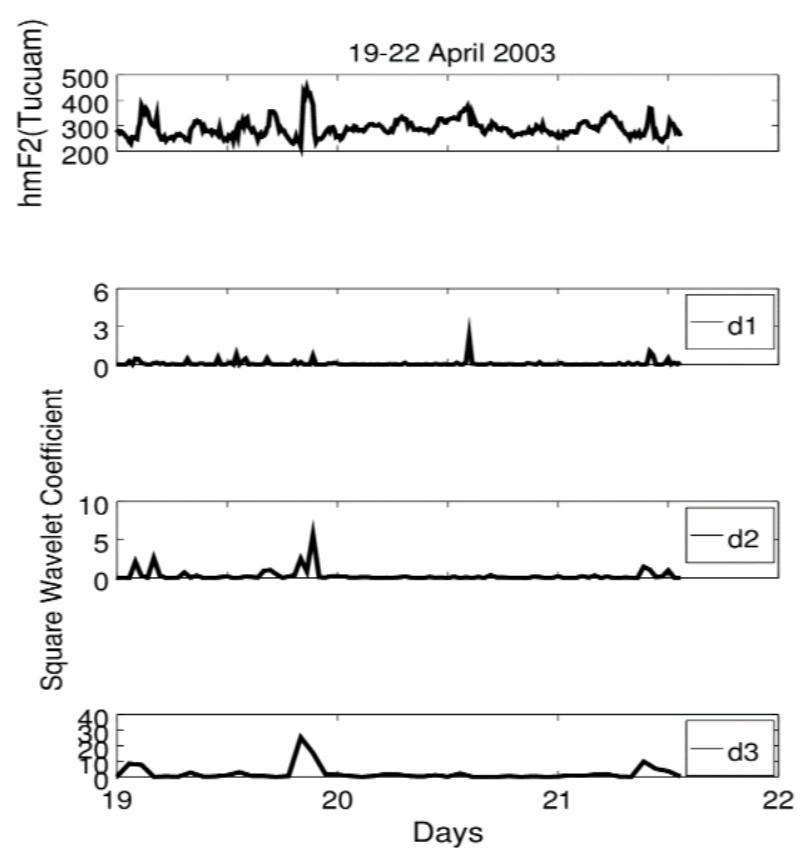

Fig. 4.The squared Daubechies Wavelet coefficients $(\text { dj })^{2}($ for $j=1,2,3)$ for $\mathrm{hmF2}$ component during HILCAA events in between 19-22 April, 2003. 
Figure 4 illustrates information on the results of discrete wavelet transform $\mathrm{hmF} 2$ during same event from 19 to 22 April, 2003. The higher amplitudes of the square wavelet coefficients indicate the singularities or discontinuities in records associated with geomagnetic storm or HILDCAA. Smaller and larger amplitude of square wavelet coefficients indicate calm and disturbed conditions of magnetosphere respectively. This technique has identified the sudden variations on $\mathrm{hmF} 2$ at the time of HILDCAA.
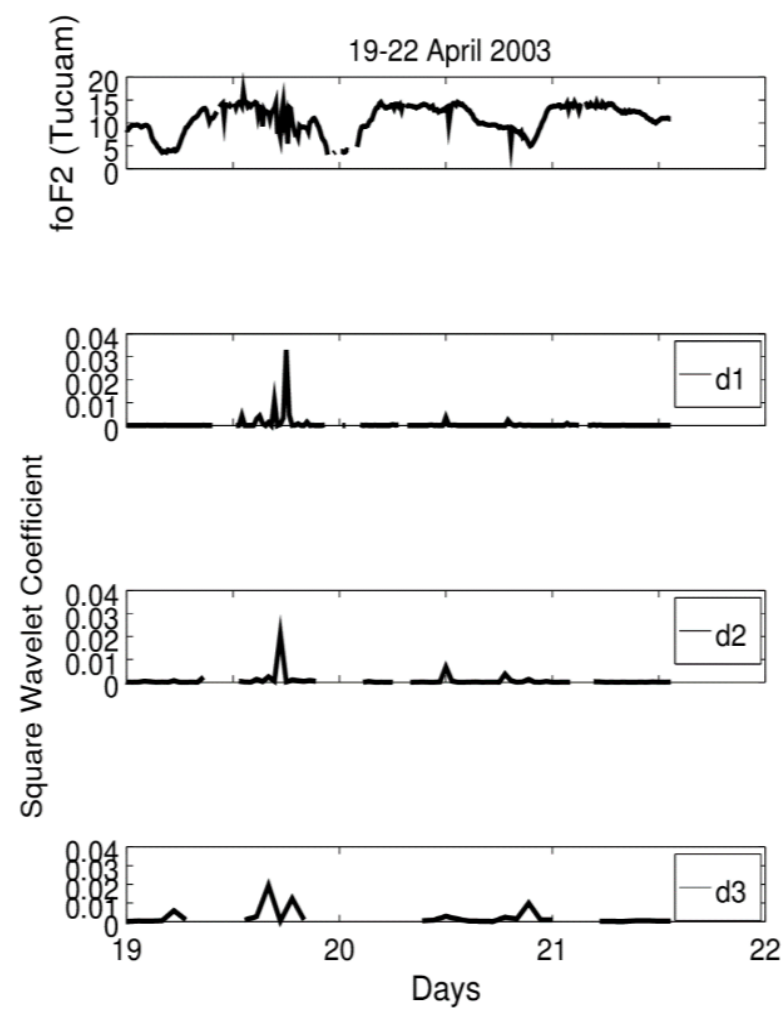

Fig. 5. The squared Daubechies Wavelet coefficients $(d j)^{2}($ for $j=1,2,3)$ for foF 2 Component during HILCAA events in between 19-22 April, 2003.

Figure 5 elucidates information on the results of discrete wavelet transform for foF2 during the same event from 19 to 22 April, 2003. The higher amplitudes of the square wavelet coefficients indicate the singularities or discontinuities associated with HILDCAA. Smaller and larger amplitude of square wavelet coefficients indicate calm and disturb conditions of magnetosphere respectively. The major objective of this technique is to indicate the sudden fluctuations that occur on foF2 during HILDCAA.
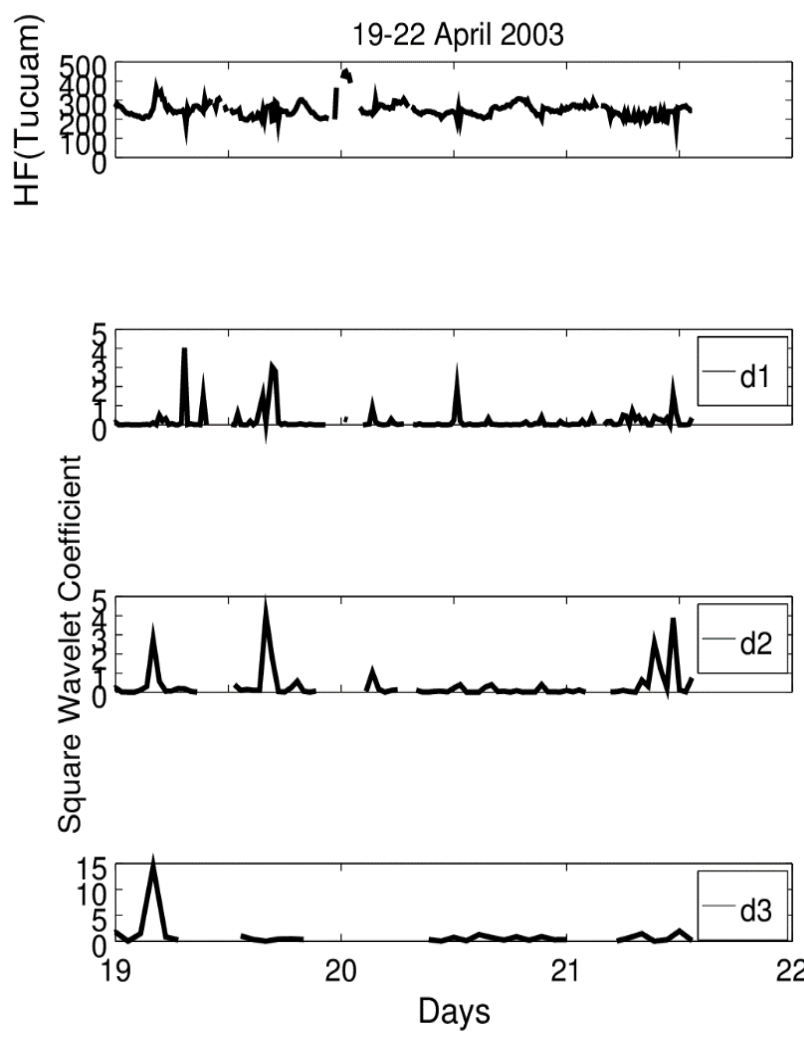

Fig. 6. The squared Daubechies Wavelet coefficients $(\mathrm{dj})^{2}($ for $j=1,2,3)$ for $\mathrm{hF}$ component during HILCAA events in between 19-22 April, 2003.

Figure 6 points out the information on the results of discrete wavelet transform for $\mathrm{hF}$ during same event. The higher amplitudes of the square wavelet coefficients indicate the singularities or discontinuities produced during HILDCAA. Smaller and larger amplitude of square wavelet coefficients indicate calm and disturb conditions of magnetosphere respectively. The main objective of this technique is to identify the sudden variations that occur on $\mathrm{hF}$ at the time of HILDCAA.

\section{CONCLUSION}

During HILDCAA, the increased rate of photoionization and its recombination leads to the variation of $\mathrm{foF}_{2}, \mathrm{hmF}_{2}$ and $\mathrm{hF}$ on the ionosphere. The increased solar flux is taken as the main factor for the variation on these parameters. Our analysis showed that no sharp variation on foF2 has been observed during HILDCAA. It shows significant fluctuation and variation on ionospheric parameters can be easily noticed. However, the maximum value of $\mathrm{hF}$ and $\mathrm{hmF} 2$ observed on the mid-day of $111^{\text {th }}$ day. The maximum value of $\mathrm{hF}$ and $\mathrm{hmF} 2$ are 
observed on the mid-day of $111^{\text {th }}$ day. The depression in $\Delta \mathrm{H}$ component and SYM-H index deeps below the reference level whereas ASY-H has positive values which goes to some maximum value of about $85 \mathrm{nT}$. The intense activity in $\mathrm{AE}$ index noticed from mid-day of $110^{\text {th }}$ day to the beginning of $113^{\text {th }}$ day. The variation in $\mathrm{AE}$ conforms that during HILDCAA there is continuous injection of charged particles inside the polar region. Moreover, it shows that during HILDCAA events, the component of magnetic field shows high level of fluctuations due to the presence of Alfven waves. This fact can also be corroborated by fluctuations in density and speed of the solar wind plasma.

\section{ACKNOWLEDGEMENTS}

The solar wind, ionospheric (Tucuam station)and magnetometer (Vassouras station) datasets were downloaded from the web pages: www.omni.nasa.org, www.cdaweb.gsfc.nasa.gov and www.intermagnet.org. respectively. We would like to thank the websites for the high resolution datasets for our research.

\section{REFERENCES}

Adhikari, B. and Chapagain, N. P. (2015). Polar cap potential and merging electric field during high intensity long duration continuous auroral activity. Journal of Nepal Physics Society, 3 (1): 6-17.

Adhikari, B.; Baruwal, P. and Chapagain, N. P. (2016). Analysis of supersubstorm events with reference to polar cap potential and polar cap index. Earth and Space Science, 3: 2-15.

Adhikari, B.; Adhikari, R.; Chapagain, N. P.; Sapkota, N.; Dahal, S. and Pandit, D. (2017). Daily, Seasonal and Monthly Variation of Middle-low latitudes Magnetic Field during Low Solar Activity. Discovery, 53 (255): 181-190.

Chapman, S. and Bartels, J. (1940). Geomagnetism. [S.1.]: Clarendon Press, Oxford, Vol-2.

Chui, C. K. (1992). An Introduction to Wavelets, Academic Press, San Diego, 266.

Daubechies, I. (1992). Ten lectures on wavelets [S.1.]: Society for Industrial and Applied Mathematics, PA, USA.

Dungey, J. (1961). Interplanetary magnetic field and the auroral zones. Physical Research letters, 6: 47.
Gonzalez, W. D.; Josely, J. A.; Kamide, Y.; Korehl, H. W.; Rostoker, G.; Tsuruntani, B. T. and Vasylianas V. M. (1994). What is a geomagnetic storm? Journal of Geophysical Research, 99: 5771-5792.

Gonzalez, W. and Tsurutani, B. T. (1987). Criteria of interplanetary parameters causing intense magnetic storms (dst< -100 nT). Planet Space Science, 35: 1101.

Gonzalez, W.; Tsurutani, B. T. and Gonzalez, A. (1999). Interplanetory Origin of Geomagnetic Storms. Space Science Reviews, 88: 529-562.

Grossmann, A. and Morlet, J. (1983). Decomposition of Hardy functions into square integrable wavelets of constant shape. SIAM Journal on Mathematical Analysis, 15: 723-773.

Guarnieri, F. L. (2006). The nature of auroras during high-intensity long-duration continuous AE activity (HILDCAA) events: 1998 to 2001. In: BT Tsurutani et al. (eds) Recurrent Magnetic Storms: Corotating Solar Wind Streams. Geophysical Monogram Series, AGU, Washington, D. C., 167: 235-243.

Hajra, R. B. T.; Echer, E.; Bruce, T.; Tsurutani, B. T. and Gonzalez, W .D. (2013). Solar cycle dependence of High-Intensity LongDuration Continuous AE Activity (HILDCAA) events, relativistic electron predictors? Journal of Geophysics Research, 118: 5626-5638.

Hajra, R.; Echer, E.; Tsurutani, B. T. and Gonzalez, W. D. (2014b). Solar wind-magnetosphere energy coupling efficiency and partitioning: HILDCAAs and preceding CIR storms during solar cycle 2. Journal of Geophysics Research, 119, doi 10.1002/2013JA019646.

Hajra, R.; Echer, E.; Tsurutani, B. T., and Gonzalez, W. D. (2014a). Superposed epoch analyses of HILDCAAs and their interplanetary drivers: solar 25 cycle and seasonal dependences, 121: doi:10.1016/ j.jastp.2014.09.012.

Klein, L. W. and Burlaga, L. W. (1982). Interplanetary magnetic clouds at $1 \mathrm{AU}$, Journal of Geophysical Research, 87: 613-624.

Klausner, V.; Mendes, O.; Domingues, M. O.; Papa, A. R. R.; Tyler, R. H.; Frick, P. and Kherani, E. A. (2014). Advantage of wavelet 
technique to highlight the observed geomagnetic perturbations linked to the Chilean tsunami (2010). Journal of Geophysics Research Space Physics, 119: 3077-3093.

Lakhina, G. S.; Alex, S.; Tsurutani, B. T. and Gonzalez, W. D. (2005). Research on Historical Records of Geomagnetic Storms. In: K., Dere, J. Wang, and Y. Yan (eds). Coronal and Stellar Mass Ejections. IAU Symposium, 226: 3-15.
Rostoker, G. (1972). Geomagnetic indices. Review of Geophysics and Space Physics, 10: 935-950.

Mendes, O. J. and Domingues, M. O. (2005). Mendes da Costa, A wavelet Analysis Applied to Magnetograms. Journal of Applied and Solar Terrestrial Physics, 67: 1827-1836.

Wei, C. Q.; Sanson, J. C.; Rankin, R. and Frycz, P. (1994)0. Electron inertial effect on geomagnetic field line resonances. Journal Geophysics Review, 99: 11265. 